\title{
Determination of mechanical properties of carbon/epoxy plates by tensile stress test
}

\author{
Paul Bere ${ }^{1}$, and Jolanta B. Krolczyk ${ }^{2, *}$ \\ ${ }^{1}$ Technical University of Cluj-Napoca, Faculty of Machine Building, B-dul Muncii 103 - 105, RO-400641 Cluj-Napoca, Romania \\ 2 Opole University of Technology, Faculty of Mechanical Engineeing, Proszkowska 76, 45-758 Opole, Poland
}

\begin{abstract}
The polymeric composite materials used in aerospace, military, medical or racing cars manufacturing end up being used in our daily life Whether we refer to the performing vehicles, subassemblies or parts for aircrafts, wind, telegraph poles, or medical prostheses they all are present in our lives and they are made of composite materials (CM). This paper presents research regarding three different composite materials, plates by carbon fiber, in epoxy matrix. Starting with materials presentation, manufacturing methodology and determination of mechanical properties at carbon fiber/epoxy were done. Vacuum bag technology to obtain the composite structure offer opportunity to get a very compact and homogeny composite structure. For the moment this technology are adequate for high performances pieces. The mechanical characteristics of plates made of composite materials reinforced presented indicates closed value like metal materials. Based on the results, a comparative study between the reinforced materials typically used to manufacture the plates of CM is carried out.
\end{abstract}

\section{Introduction}

The design of new applications requires investigating in area of new materials, including composites or bimetals [1-3]. Vast studies on current issues facing the use of CM [4-6] have been concentrated on the extensive investigations in which relate to aspects of composite materials in vehicle construction [7-9]. The CM since 1975 has a very impressive development. These materials entered our everyday life after a time made in the top areas of global technology. Further development of composite materials, particularly in the last 40 years has led to some investigations that reveal both their properties and shortcomings.

The migration of $\mathrm{CM}$ of high-performance areas to daily areas is in a continuous and sustained rate. Used in a military, aviation, motorsport, or medical domain the $\mathrm{CM}$ arrives in the domestic areas like agriculture, furniture's, arts, or building constructions. The physicalmechanical properties of these materials require the use more frequently. Polymeric reinforced Composite materials successfully replace the traditional metallic materials.

The use and manufacture of polymer composite plates has seen a steady and also impressive development. Replacing the plates made of metal, with plates made of reinforced composite materials has led to the reduction of the weight while obtaining high mechanical characteristics. The usually technologies used for manufacturing reinforced polymeric plates are hand lay-up process, hand lay-up and pressing and vacuum bag technology. The physical and mechanical properties of carbon/epoxy composite presented in open literature [10-16]. In the same time the presented results indicate a low density of materials in condition where mechanical properties are similar to metals.

This paper obtain the performant and compact plates by $\mathrm{CM}$ and use in the vacuum bag technology. For obtaining the mechanical properties, the samples were subjected the tensile testing. Three different reinforced materials to obtain the composites plates were tested by carbon fiber/epoxy matrix.

The goal of this paper is to determinate how the type of materials architecture has influence the tensile strength of carbon fibre. The paper presented the materials and the manufacturing methodology to obtain the carbon fibre/epoxy plates, and the mechanical properties evaluation in tensile strength case. The morphology of the damaged area of the carbon samples are investigates. At the final, the authors presented a comparative study regarding the results obtained for carbon /epoxy composite plates.

\section{Manufacturing method}

\subsection{Materials}

Experimental research aimed at determining the tensile stress characteristics of composite plates. Epoxy resin, type Epiphen RE 4020/DE 4020 was used for the matrix. The mixing ratio parts by weight were 100:30, according to manufacturer recommendations.

Epoxy resin Epiphen RE 4020 / DE 4020 characteristics:

- Aspect: transparent,

* Corresponding author: j.krolczyk@po.opole.pl 
- Pot life at $20^{\circ} \mathrm{C}-45 \mathrm{~min}$,

- Brookfield Viscosity at $25^{\circ} \mathrm{C}-300 \mathrm{MPa} . \mathrm{s}$,

- Gelling time (thin layer in hours at $20^{\circ} \mathrm{C}$ ), 8 - 9 hours,

- Density la $25^{\circ} \mathrm{C}-1150 \mathrm{~kg} / \mathrm{m} 3$,

- Curing at $20^{\circ} \mathrm{C}, 24$ hours.

The reinforcement material used was a biaxial carbon fiber fabric by $0-90^{\circ}$ plain, twill and unidirectional weave fabric $3 \mathrm{~K}, 200 \mathrm{~g} / \mathrm{m}^{2}$ ). The samples codes used in the paper for types of fabric are: plain $\mathrm{P}$, twill $\mathrm{T}$ and unidirectional UD. The technology to obtain the plates keeps initial architecture of reinforced material.

\subsection{Samples parts manufacturing}

For obtaining the composite samples were used the vacuum bag technology (Fig. 1). In initial stage the wet technology and hand lay-up process was used. This procedure realize a good impregnation of the reinforced material.

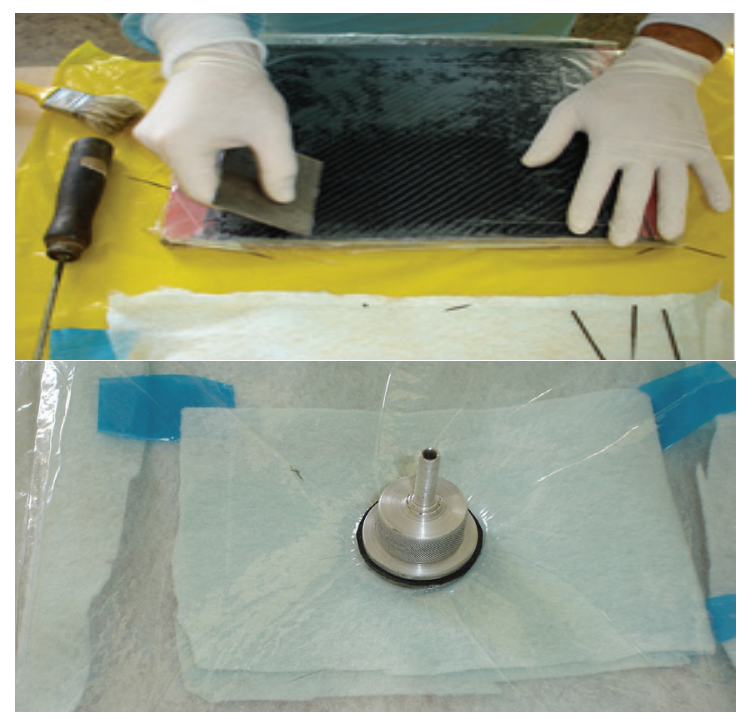

Fig. 1. Composite plates manufacturing process.

Different plates from carbon fibre/epoxy fabrics were manufactured. The impregnation of the carbon fibre material was done on the metal plates mould. Initially the surface of the mould was traded using the mould sealer tip Frekote B15 Aero by Loctite. Several times of mould sealer were applied. This agent prevents the bonding of the carbon fibre/epoxy on the mould surface.

The hand lay-up technology was used to have a good impregnation of the carbon fibre. All the layers were applied a mould and covered with a perforated plastic folia and breather fabric. All the system was covered by a vacuum bag foil. At the border the bag was closed by vacuum sealing type.

On the bag has been applied a vacuum pressure of 0.9 Bar. This pressure eliminates all the air bubbles from composite materials and the excess of the resin. The atmospherics pressure creates a compact CM with a very thin and uniformed structure.

During the polymerization time of composite material applied vacuum was maintained. The polymerization process was made in an oven at $80^{\circ}$ time to 8 hours.

After polymerization time the auxiliary materials are rejected and the plates are release. To determinate the psychical and mechanical properties of the plates the borders are cute until homogeny structure.

From all CM plates P, T, UD, five samples sets for tensile stress tests were manufacturing. The dimension of samples (Fig. 2) are:

$\mathrm{L}=250 \mathrm{~mm}$ (including $\mathrm{TABs}$ ) $, 1=200 \mathrm{~mm}, \mathrm{~b}=20 \mathrm{~mm}$, $\mathrm{h}=0.7-2.3 \mathrm{~mm}$.

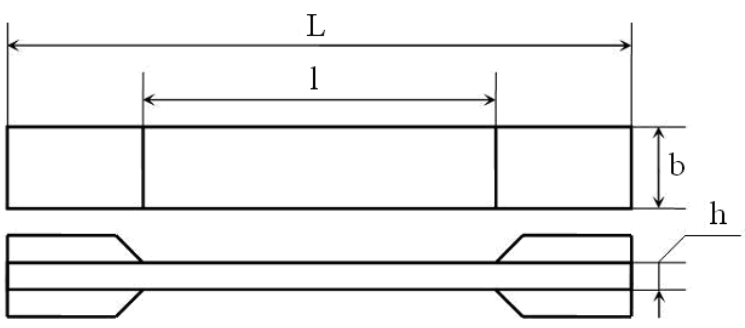

Fig. 2. Sample dimension according to the EN ISO 527-4 and ISO 527-5 standard.

The samples were cut by water jet technology. The water jet machine type OMAX 2626 was used. To prevent the samples delamination during the water jet penetration time of the carbon composite plates, the penetration water jet area was positioned at $40 \mathrm{~mm}$ distance from the samples border [17-19].

The samples dimensions were compliant according standards EN ISO 527-4 and ISO 527-5 [20, 21].

The ends of the specimens were reinforced with a 2 $\mathrm{mm}$ thick, 20-35 mm glass fabric TABs in order to avoid the slippage and breakage of specimens at clamping. The TABs were fixed on the specimens with a structural adhesive (3M Scotch-Weld $9323 \mathrm{~B} / \mathrm{A}$ ). The resistive force recorded during the tensile test was divided by the cross-sectional area of the specimen in order to determine the tensile stress.

For fracture, maximum resistance force recorded during the tensile test was related to cross-sectional area of the specimen:

$$
\sigma_{r}=F_{\max } / A
$$

The samples were loaded to failure with constant crosshead speed (5 mm/min) using an Instron 8801 (100 $\mathrm{KN})$ servohydraulic testing system All measurements were carried out at room temperature $\left(20^{\circ} \mathrm{C}\right)$ and humidity in the range of $45-50 \%$.

The samples are coded from 1 to 5 from the border to interior of the plates.

\section{Experimental results}

The obtained surfaces of composite plates copied the surface of the mould. It is not observing the air bubble on the surface. A good pressed structured are obtained. The obtained characteristics of the plates are:

- weight fraction ratio $72 \%$, 
- density of composite material $1087.97 \mathrm{~kg} / \mathrm{m}^{3}$ for carbon fiber plates.

The weight fraction ratio was calculated using equation:

$$
W_{f}=\frac{w_{f}}{w_{c}} \times 100[\%]
$$

Where was note by:

$W_{f}$-weight fiber fraction,

$w_{f}-$ weight of reinforced material,

$w_{c}$ - weight of composite materials.

Obtained values of tensile tests it was processed. The sets of samples were marked.

For carbon-epoxy samples the main values of tensile stress are:

\section{UD -1050 MPa; Plain -570 MPa; Twill $525 \mathrm{MPa}$}

The breaking area of the carbon/epoxy samples is different. In the carbon/epoxy case the maximum stress produce like on explosion at the samples. The sample was broken on many pieces. In all the cases the stress of the samples is accompanied by acoustic emission and this predicting catastrophic breakage.

A force/displacement diagram is presented in Fig. 3 carbon fiber (plain weave fabric $3 \mathrm{~K}$ by $200 \mathrm{~g} / \mathrm{m}^{2}$ ) /epoxy.

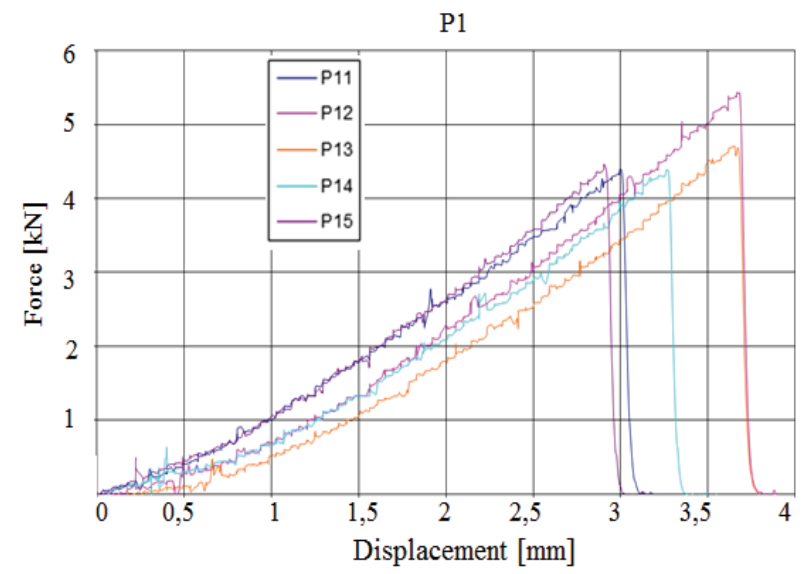

Fig. 3. Force-displacement diagrams experimentally determined for samples of carbon fiber (plain weave fabric $3 \mathrm{~K}$ by $200 \mathrm{~g} / \mathrm{m}$ ) /epoxy.

In Fig. 3 are presented the comparative diagrams for all five P samples subjected by tensile stress test (P11 represent the first sample cut form carbon plate, and the $\mathrm{P} 15$ the last sample). The samples are noted with different colours. On $X$ axe are presented variation of displacement (elongation) of the samples and on Y axe the variation force during the traction request. The force/displacement diagram shows a linear elastic behaviour at the $\mathrm{CM}$ until fracture zone when they are depreciating suddenly. The force/displacement diagram shows a linear elastic behaviour at the $\mathrm{CM}$ until fracture zone when they are depreciating suddenly.

This behaviour is typical for fiber reinforced composite materials in which the direction of the fibers is the direction of the request. In this case longitudinally arranged filaments have contributed to the high value of fracture strength. It should be noted that for the balanced used fabric only half of the filaments used opposed traction application. The other halves of the filaments were arranged transversely to the direction of application. A normal behaviour for CM is indicating in the diagram where we can see an elastic area. The elongation of the samples is $0.2 \%$ for a maximum stress. The analysis of microstructure fracture area from fibers carbon/epoxy sample relieve the carbon fiber monofilament simultaneously grouped and broken (Fig. 4).

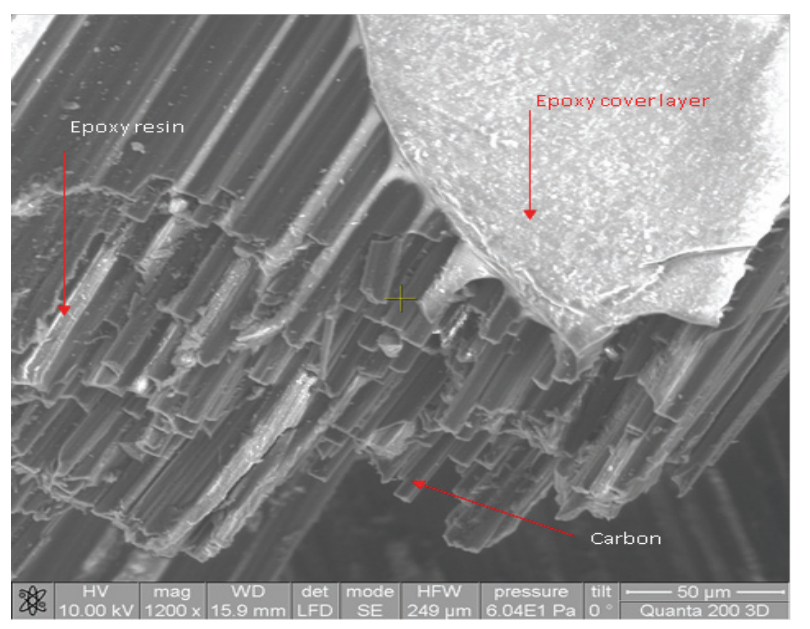

Fig. 4. Microstructure fracture area of CM sample subjected by tensile test.

No individual monofilaments are observed, tensile request being taken over by groups of filaments that have acted together. It appears a good impregnating matrix and a good compatibility between filaments and matrix. The epoxy matrix parts remain bonded on carbon fibre monofilaments after tensile test. In the same time in the figure presented we can see the matrix impregnate the monofilaments and cover it.

The morphology of the structure was investigated using scanning electron microscopy SEM type Quanta 200 3D DUAL BEAM.

If compare this three types of carbon/epoxy the maximum tensile stress $(1050 \mathrm{MPa})$ were obtained in UD Carbon/epoxy case. The results presented in Fig. 5 classify these $\mathrm{CM}$ at tensile stress from this point of view.

In the fabrics type of materials cases it can be observed a normal behaviour where the tensile strengths are in the fabrics of carbon fibre structure only half of monofilaments are on force direction applied approximatvely half of the UD carbon fibre.

Half of these are applied perpendicular on force direction. In the same time we can observe that in the carbon fibre twill tissue the tensile strength increase. This type of material have very good facilitates in the complex three dimensional surfaces. The twill fabrics fit very well on the complex surfaces and respect the curve of surface (the creases not appear).

The tensile strength obtained are very high comparable with metals. However we must to thinking that the density of material is 7 times lower. 


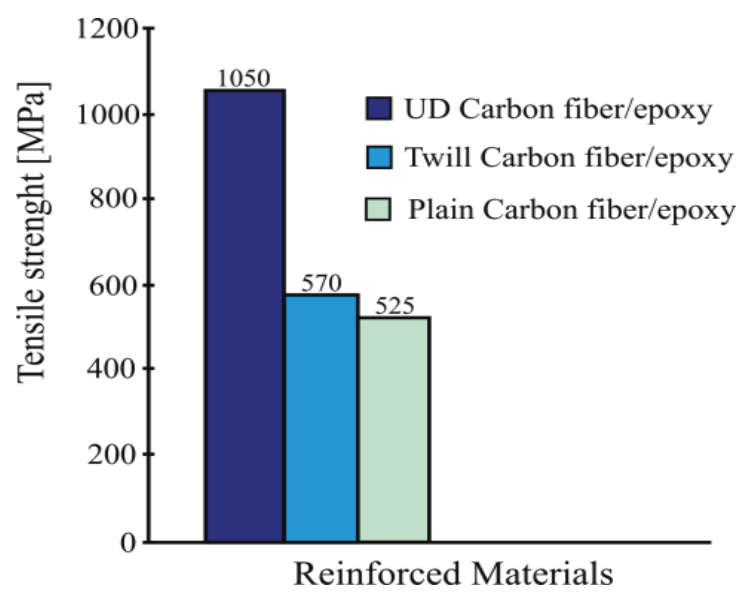

Fig. 5. Comparative diagram between tensile strength and materials type of $\mathrm{CM}$

\section{Conclusions}

Three different architecture types of carbon fibre/epoxy matrix plates were investigated. The manufacturing methods by vacuum bag technology indicate a height performance obtained by CM. The density of carbon/epoxy obtained plates is seven times lower than steel and twice as aluminium alloys. Microstructure of the material indicates a very good impregnation of the carbon fibre and the good compatibility between fibres and the matrix. The technology used, materials, the polymerisation and thermal treatments indicate a special material class obtained.

According to the mechanical properties in tensile strength case, the authors relive the different between types of fibre architectures for the same materials.

The novelty of the problem is to emphasize for the composite designers the different results between the same types of the materials but using different architecture type. In the same time showing which technology can be applied to obtain these results.

Following the results of tensile stresses in composite plates we see that the highest value is obtained by UD carbon/epoxy $\mathrm{CM}$. The values of these materials are ultimate tensile stress at $1050 \mathrm{MPa}$ at UD type case. In this case all the monofilaments are arranged by request direction. The tensile strength of the composite material obtained, has a high value compared to high quality steel in terms of the density decrease of approx. 7 times in the case of M.C.

Compare the biaxial fabric, plain and twill type is observed closer values of tensile strength. For carbon twill tissue the results are 54\% lower value like UD case. In this case only half on monofilaments are positioning on request direction. Another half of these are in the transversal position. For carbon/epoxy plain tissue, obtained results regarding the tensile stress test is much closed to twill tissue. The results indicate $8 \%$ lower in balanced plain tissue case.

This work was supported by a grant of the Romanian National Authority for Scientific Research and Innovation, CNCS/CCCDI-UEFISCDI, project number PN-III-P2-2.1-BG2016-0210, within PNCDI III.

\section{References}

1. C.V. Opelt, J.M.F. Paiva, G.M. Cândido, M.C. Rezende, Eng. Fail Anal. 79, 342-350 (2017)

2. P. Nieslony, P. Cichosz, G.M. Krolczyk, S. Legutko, D. Smyczek, M. Kolodziej, Measurement 78, 129 - 137 (2016)

3. P. Nieslony, G.M. Krolczyk, K. Zak, R.W. Maruda, S. Legutko, Precis Eng. 47, 104 - 110 (2017)

4. E.E. Feldshtein, L.N. Dyachkova, Compos. Part BEng. 58, 16-24 (2014)

5. P. Valášek, A. Ruggiero, M. Müller, Compos Part B- Eng. 122, 79-88 (2017)

6. A. Ruggiero, P. Valášek, M. Müller, Compos Part B- Eng. 104, 9-16 (2016)

7. R.M. Jones, Mechanics of Composite Materials. Taylor and Francis (Philadelphia, 1999)

8. L.P. Kollar, G.S. Springer, Mechanics of Composite Structures (Cambridge University Press, Cambridge, 2003)

9. V.V. Vasiliev, E.V. Morozov, Mechanics and Analysis of Composite Materials (Elsevier Science, London, 2001)

10. T. Sathishkumar, S. Satheeshkumar, J. Naveen, J Reinf, Plast. Compos. 33, 1258-1275 (2014)

11. J. M. Stickel, M. Nagarajan, Int J Appl Glass Sci 3, 122-136 (2012)

12. S. C. Amico, C. C. Angrizani, M. L. Drummond, J Reinf. Plast. Compos. 29, 179-189 (2010)

13. M. S. M. Jusoh, C. Santulli, M. Y. M. Yahya, N. S. Hussein, H. A. I. Ahmad, Mate. Sci. Eng. Adv. Res. 1, 19-25 (2016)

14. E. H. Portella, D. Romanzini, C. C. Angrizani, S. C. Amico, A. J. Zattera, Mater. Res. 19, 542-547 (2016)

15. P. Bere, Theoretical and experimental research on the manufacturing and mechanical behaviour of the tubes made from polymeric composite materials, $\mathrm{PhD}$ thesis, Technical University of Cluj-Napoca, Romania (2009)

16. G. L. Enachescu, M. F. Stefanescu, J. Plastic Mater. 53, 198-201 (2016)

17. V. Miron, N. Balc, A. Popan, C. S Borzan, P. Bere, AJME 11, 2, 87-92 (2013)

18. Popan, N. Balc, A. Carean, A. Luca, AJME 10, 3, 97-102 (2012)

19. I.A. Popan, N. Balc, A. Carean, A. Luca, V. Ceclan, AJME 11, 3, 17-22 (2011)

20. ISO 527-4 2: 1997, Plastics - Determination of tensile properties. Test conditions for multidirectional fiber - reinforced plastic composites.

21. ISO 527-5 A, B: 1997. Plastics - Determination of tensile properties. Test conditions for unidirectional fiber - reinforced plastic composites. 